\title{
Functional gastrointestinal disorders: psychological, social, and somatic features
}

\author{
E J Bennett, C Piesse, K Palmer, C-A Badcock, C C Tennant, J E Kellow
}

\begin{abstract}
Background-Psychological, social, and extraintestinal (somatic) disturbances are prominent features of functional gastrointestinal disorders (FGID); little attention, however, has been given to differences in the nature of these disturbances in the various FGID subgroups.

Aims-(1) To determine whether psychological, social, and extraintestinal factors are associated with specific FGID, and/or with the overall severity and extent of FGID disturbance (the number of coexistent FGID subgroups present in any individual); and (2) to determine whether chronic social stressors link gastrointestinal, extraintestinal, and emotional symptomatologies in FGID.

Patients-One hundred and eighty eight outpatients, fulfilling standard criteria for one or more functional gastroduodenal or functional bowel disorders.

Methods-Utilising detailed and objective interview and questionnaire methods, detailed gastrointestinal, extraintestinal, psychological, and social data were collected.

Results-Chronic stressors and extraintestinal and emotional symptomatologies were prominent features of functional dyspepsia (FD) and irritable bowel syndrome (IBS) alone. These particular features were, however, highly specific for particular FD and/or IBS subgroups. The chronic threat component of social stressors predicted the nature and extent of multisystem (gastrointestinal, extraintestinal, and emotional) symptomatology. Conclusions-Notable differences between the various FGID subgroups support the symptom based classification of FGID. Chronic stressor provoked psychological and extraintestinal disturbance is most specific for the FD-IBS group of syndromes.

(Gut 1998;42:414-420)
\end{abstract}

Keywords: functional gastrointestinal disorders; psychosocial; extraintestinal symptoms; chronic stress

The functional gastrointestinal disorders (FGID) are common disorders in gastroenterology practice and in the community. Although several FGID syndromes may coexist in an individual patient, each syndrome can be reliably identified as a distinct and homogeneous entity. ${ }^{1}$ Psychological, social, ${ }^{2-4}$ and extraintestinal (somatic) disturbances ${ }^{5-9}$ are prominent features of FGID in general; whether such factors are distinctive of specific FGID syndromes or subgroups (distinct clusters of symptoms), or whether they reflect the overall severity and/or extent of functional gut disturbance (number of coexistent FGID syndromes), has received little attention. Furthermore, although social stressors that are severe, chronic, and threatening have been implicated in the development of FGID, ${ }^{34}$ no study has previously assessed the relation of specific objective measures of social stressors to coexistent gastrointestinal, extraintestinal, and emotional symptomatologies in the FGIDs.

Our specific aims were therefore, in a large group of patients with various functional gastroduodenal and functional bowel disorders, to determine: (1) the relative importance of specific psychological, social, and extraintestinal (somatic) factors to specific FGID, and/or to severe and extensive functional gut disturbance; and (2) whether the nature and severity of concurrent gastrointestinal, extraintestinal, and emotional symptomatologies are predicted by the severity of the threat component of chronic social stressors. Specific profiles, comprising factors which together predicted each outcome, were determined using a method of analysis that adjusts for the presence of other FGID, as well as for age, gender, demographic, and other factors.

\section{Methods}

PATIENTS

Outpatients with FGID ( $\mathrm{n}=188,135$ women, aged 44 (12) years), who satisfied the inclusion criteria for the study, were recruited consecutively from individuals referred by their general practitioner for endoscopic evaluation by members of the Department of Gastroenterology. Inclusion criteria were: symptom criteria for one or more of the FGID subgroups (functional gastroduodenal disorders, functional bowel disorders, or functional abdominal pain syndrome ${ }^{1}$ ); absence of organic disease by appropriate investigations; age less than 70 years; and no difficulty conversing in English. The patient sample comprised $95 \%$ of eligible patients; reasons for non-participation were time and/or major geographical constraints. All patients underwent a detailed semistructured interview, and also completed self report psychological and symptom questionnaires; psychosocial and symptom data were collected in a blinded and independent manner. The protocol was approved by the Medical Research Ethics Committee of the Royal North Shore Hospital, and all patients gave written informed consent. 
SYMPTOM ASSESSMENTS

Gastrointestinal symptoms

FGID symptom subgroups were defined strictly according to the criteria (based on the Rome criteria) elaborated by Drossman. ${ }^{1}$ Classification of patients into these subgroups was determined from responses on the Bowel Disease Questionnaire (BDQ) ${ }^{10}$ after minor revision of questionnaire items to accommodate all of the above criteria; a recent version of the BDQ has been validated in an Australian population. ${ }^{11}$ Subgroups assessed ${ }^{1}$ included functional dyspepsia (FD) - namely ulcer-like (UL) dyspepsia, dysmotility-like (DL) dyspepsia, reflux-like (RL) dyspepsia, and unspecified (non-specific) dyspepsia (UFD); functional bowel disorders (FBD) - namely irritable bowel syndrome (IBS), functional constipation (FC), functional diarrhoea (FDiar), and unspecified functional bowel disorder; and functional abdominal pain syndrome. RL dyspepsia (defined as upper abdominal discomfort, plus heartburn and/or regurgitation at least once a week, for three months or more ${ }^{12}$ was included because these latter symptoms frequently overlap with UL and DL dyspepsia and with IBS. The appropriate subgroup classification was determined by one investigator (CP) who was unaware of the psychosocial data. A decision was taken that aerophagia and functional abdominal bloating could not be diagnosed readily from questionnaire responses alone; these subgroups were therefore not included. Apart from those FGID subgroups which were by definition mutually exclusive, independence among subgroups was assumed.

A semistructured interview assessed, over the previous two weeks: (1) the intensity of current FD and IBS symptoms - namely the product of symptom frequency and severity; (2) the constancy in FD or IBS of "upper" and "lower" abdominal pain and discomfort using a five point scale where $1=$ episodic (discrete, infrequent bouts); 2 = periodic remissions (more than one month between brief bouts); 3 = constant (more than three bouts per fortnight); 4 = constant daily; and $5=$ always present, day and night; and (3) the duration of this pattern prior to presentation for endoscopy.

\section{Extraintestinal (somatic) symptoms}

A modified version of the Psychosomatic Symptom Checklist ${ }^{10}$ was used to ascertain the presence (more than $25 \%$ of the time during the past three months) of concurrent extraintestinal symptoms (EIS), namely fatigue, tension headaches, migraine headaches, unpleasant taste, nocturia, urinary frequency/urgency, incomplete bladder emptying, dry skin (eczema-like), insomnia, and backache. Several habitual behaviours were also assessed, including binge eating ${ }^{13}$; no patient fulfilled the criteria for bulimia nervosa, and none had used inappropriate compensatory behaviours (for example, self induced vomiting) during the current FGID episode or for at least the previous six months.
PSYCHOSOCIAL ASSESSMENTS

Psychosocial data were collected and processed by one investigator (EB) who was unaware of FGID subgroup diagnoses.

\section{Semistructured interview}

This gathered information relevant to social stressors and emotional support. The Life Events and Difficulties Schedule (LEDS) ${ }^{14}$ was used to elicit detailed information, during an interview of approximately two hours duration, about discrete life events and chronic difficulties (defined as six months or more) that were current during the previous six months - their onset, duration, type, intensity (in terms of provoking a strong emotional response such as fear, flight or fright, anger or frustration), and broad social context. Biographical or personal information (for example, adoption, child abuse, immigration, multiple miscarriages) of relevance to the particular meaning of the stressor (what was at stake for an individual in those circumstances), was also recorded. With no reference to the subject's own emotional response, these objective (externally verifiable) data were presented by the interviewer in vignette form to an experienced rater (KP). In essence, the stressor rating provides a measure of the degree of threat innate in the circumstances (that is, to the person's security, future well being, personal integrity, etc) and the degree of goal frustration such a happening may have provoked (for example, by obstructing specific personal aims, needs, and ambitions). Clinical validity and reliability have been established for the LEDS method ${ }^{15}$ and inter-rater reliability is high. ${ }^{15}$ Only stressors that were judged to be independent of FGID symptoms were coded for analysis. Each stressor was rated separately for emotional threat and for goal frustration on a four point scale where $0=$ mild; $1=$ moderate; $2=$ severe; and $3=$ very severe. For each individual, the threat and goal frustration components of each stressor may differ considerably. In addition to the life stress variables used in previous studies of FGID,$^{34}$ two global chronic stressor scores were calculated for each patient: a chronic threat score (the sum of the threat ratings across all chronic stressors), and a chronic goal frustration score. Utilising the interview, vignettes, and ratings, the availability and quality of emotional support was recorded for intimate persons in the social network; the reliability of these latter dimensions has been established. ${ }^{16}$

\section{Questionnaires}

These assessed demographic factors (age, sex, and marital, educational, and occupational status) and the following psychological variables.

Emotional distress/current mood state-(1) Depression (Centre of Epidemiological Studies Depression Scale, CES-D) ${ }^{17}$; and (2) state anxiety (items to assess primarily the tension and apprehension aspects of a transient, or a more prolonged, anxiety state) (Spielberger State and Trait Anxiety Inventory, STAI).$^{18}$

Personality - (1) Neuroticism - to assess negative emotionality which predisposes to more intense and prolonged stress responses; 
and extraversion-introversion-to assess direction of interest to things external versus internal (Eysenck Personality Questionnaire, EPQ) ${ }^{19}$; (2) trait anxiety-to assess the tendency to anxiety states $($ STAI $))^{18}$; (3) trait anger-to assess anger temperament, and anger reactivity (the tendency to react readily with anger) (Spielberger's State-Trait Anger Scale $)^{20}$; and (4) hypochondriasis - to assess inappropriate worries and concerns about one's health (nine item subscale of Illness Behaviour Questionnaire, IBQ). ${ }^{21}$

Coping style-Use of immature, neurotic, or mature defences (Defense Style Questionnaire, DSQ). ${ }^{22}$

Emotional expression/suppression-(1) Suppressed anger, suppressed anxiety, suppressed depression - to indicate the degree of control or suppression of these unwanted emotions (Courtauld Emotional Control Scale, CECS) ${ }^{23}$; and (2) anger in, anger out, anger control-to assess the tendency to hold in or to express anger, or to control and/or to resist becoming angry (Anger Expression (AX) Scale).$^{24}$

The psychometric properties of the above measures have been established. An emotional disorder of probable clinical significance was differentiated from (milder) emotional distress using the cut off scores of 17 and 57 for depression ${ }^{25}$ and state anxiety ${ }^{18}$ scales respectively.

\section{STATISTICAL ANALYSIS}

Logistic regression using the forward stepwise model selection approach was used to determine the significant factors related to each of the FGID syndromes; this method ensured that the selection of primary features for each syndrome was based on conditional probabilities, while each analysis simultaneously adjusted for the presence of other syndromes. Linear regression analysis was used when the dependent variable was continuous (number of FGID). At each step of the forward stepwise procedure, the most significant of the independent variables was entered first (criterion for entry was $p<0.05)$. Each variable was retained in the final model only if significance remained at $\mathrm{p}<0.05$ - that is, all variables in the predictor models/regression equations reported in this study contribute significantly $(p<0.05)$ to the outcome. Independent variables included demographic, psychosocial, and extraintestinal factors; gender was included in most analyses as an independent variable. Covariates, which included other FGID syndromes, symptom intensity, constancy, and duration, emotional distress, and demographic variables, were introduced appropriately into the analyses. Two tailed Pearson correlation analysis tested the linearity and strength of relationships between pairs of multisystem variables-number of FGID, number of EIS, anxiety, and chronic threat.

\section{Results}

NUMBER AND TYPE OF FGID SYNDROMES

Table 1 summarises the prevalence of FGID syndromes and their subgroups. The majority $(167,89 \%)$ of patients were classified as having
Table 1 Prevalence of functional dyspepsia (FD) syndromes, functional bowel disorders (FBD), and functional abdominal pain syndrome within the patient sample $(n=188)$

\begin{tabular}{|c|c|c|}
\hline Group/subgroup & $n$ & Sample \% \\
\hline \multicolumn{3}{|l|}{ FD syndromes $(62 \%)^{\star}$} \\
\hline Ulcer-like dyspepsia & 35 & 19 \\
\hline Dysmotility-like dyspepsia & 73 & 39 \\
\hline Reflux-like dyspepsia & 70 & 37 \\
\hline Unspecified dyspepsia & 31 & 17 \\
\hline \multicolumn{3}{|l|}{ FBD $(89 \%) \dagger$} \\
\hline Irritable bowel syndrome & 122 & 65 \\
\hline Functional constipation & 17 & 9 \\
\hline Functional diarrhoea & 4 & 2 \\
\hline
\end{tabular}

Table 2 Psychosocial predictors of the number of FGID syndromes: the regression model of best fit

\begin{tabular}{ll}
\hline Psychosocial predictors & $\begin{array}{l}\text { Regression } \\
\text { coefficient (SE) }\end{array}$ \\
\hline $\begin{array}{l}\text { Personality } \\
\quad \text { Trait anger reactivity }\end{array}$ & $0.21(0.023)$ \\
$\quad \begin{array}{l}\text { Neuroticism (stress proneness) } \\
\text { Coping style }\end{array}$ & $0.19(0.027)$ \\
$\quad \begin{array}{l}\text { Frequent use of (mature) coping strategies } \\
\text { Life stressors }\end{array}$ & $0.18(0.006)$ \\
$\quad \begin{array}{l}\text { Chronic (social stress) threat } \\
\text { Emotional support }\end{array}$ & $0.16(0.023)$ \\
$\quad \begin{array}{l}\text { Anavailable or inadequate } \\
\text { Increasing age }\end{array}$ & $0.15(0.131)$ \\
\end{tabular}

Psychosocial predictors are presented in order of stepwise selection into the model. An increasing score on each dimension was associated with an increase in the number of FGID syndromes. Each predictor variable was significant at $\mathrm{p}$ $<0.05$ in the final model.

$\mathrm{SE}$, standard error; $\mathrm{R}^{2}=0.21$.

one FBD, and a large proportion $(117,62 \%)$ also fulfilled the criteria for one (or more) FD syndromes. The majority of patients (78\%) fulfilled criteria for two or more, and one third of patients for three or more FGID syndromes. Clusters of syndromes comprised one or more FD subgroups, with or without one of the FBDs. The FBD most likely to coexist with FD was IBS; this contrasts with other FBDs (FDiar, FC), which frequently occurred alone.

PREDICTORS OF NUMBER AND TYPE OF FGID SYNDROME

Psychological and social disturbances

Psychosocial disturbance was strongly related to the overall severity and extent of functional gut disturbance (the number of coexistent FGID subgroups present) (table 2). Thus, increases in each of the following psychosocial dimensions together predicted an increase in the number of syndromes: personality (trait anger reactivity, neuroticism); coping style (attempts to cope with stress); life stressors (featuring severe chronic threat); absent or inadequate emotional support; and increasing age. There was specificity, however, within these associations-each type of FGID syndrome was distinguished by at least one psychosocial dimension (table 3 ) and these dimensions (and sex) differed between different FGID syndromes. In contrast, no demographic factor was associated with the number or type of FGID symptomatology. 
Table 3 Psychosocial predictors of type of FGID syndrome: logistic regression models

\begin{tabular}{|c|c|c|c|}
\hline$F G I D$ & Sex & Psychological dimensions & Life stressor \\
\hline Ulcer-like dyspepsia & Male & $\begin{array}{l}\text { Trait anger reactivity } \\
\text { Model } \mathrm{X}^{2}=11 ; \mathrm{VE}=6 \%\end{array}$ & \\
\hline Dysmotility-like dyspepsia & Female & $\begin{array}{l}\text { Depression } \\
\text { Model } X^{2}=13 ; \mathrm{VE}=5 \%\end{array}$ & $\begin{array}{l}\text { Chronic goal frustration } \\
\text { Model } \mathrm{X}^{2}=5 ; \mathrm{VE}=2 \%\end{array}$ \\
\hline Reflux-like dyspepsia & & $\begin{array}{l}\text { State anxiety } \\
\text { Mature coping style } \\
\text { Trait anger temperament }\end{array}$ & Chronic goal frustration \\
\hline Irritable bowel syndrome & & $\begin{array}{l}\text { Model } \mathrm{X}^{2}=24 ; \mathrm{VE}=10 \% \\
\text { Hypochondriasis }\end{array}$ & Model $\mathrm{X}^{2}=10 ; \mathrm{VE}=4 \%$ \\
\hline & & $\begin{array}{l}\text { Anger control } \\
\text { Model } \mathrm{X}^{2}=12 ; \mathrm{VE}=7 \%\end{array}$ & \\
\hline Functional constipation & & $\begin{array}{l}\text { Anger held in infrequently } \\
\text { Anger controlled infrequently } \\
\text { Model } \mathrm{X}^{2}=18 ; \mathrm{VE}=16 \%\end{array}$ & \\
\hline
\end{tabular}

Each predictor variable (sex, psychological and life stressor) was significant at $\mathrm{p}<0.05$ in the final model. VE, variance explained.

Table 4 Extraintestinal symptom predictors of type of FGID syndrome: logistic regression models

\begin{tabular}{|c|c|c|c|c|}
\hline FGID & Sex & Extraintestinal symptoms & Odds ratio & $95 \% C I$ \\
\hline Ulcer-like dyspepsia & Male & Nil & $\begin{array}{l}2.9 \\
\mathrm{VE}=4 \%\end{array}$ & 1.32 to 6.19 \\
\hline Dysmotility-like dyspepsia & Female & $\begin{array}{l}\text { Fatigue } \\
\text { Unpleasant taste }\end{array}$ & $\begin{array}{l}3.0 \\
2.0 \\
2.2 \\
\mathrm{VE}=9 \%\end{array}$ & $\begin{array}{l}1.37 \text { to } 1.86 \\
1.07 \text { to } 3.88 \\
1.07 \text { to } 4.52\end{array}$ \\
\hline Reflux-like dyspepsia & Male & $\begin{array}{l}\text { Dry skin or eczema } \\
\text { Binge eating habit } \\
\text { Unpleasant taste }\end{array}$ & $\begin{array}{l}3.6 \\
4.2 \\
2.1 \\
2.0 \\
\text { VE }=11.5 \%\end{array}$ & $\begin{array}{l}1.52 \text { to } 8.50 \\
1.49 \text { to } 11.70 \\
1.00 \text { to } 4.33 \\
1.00 \text { to } 4.14\end{array}$ \\
\hline Irritable bowel syndrome & & Fatigue & $\begin{array}{l}2.3 \\
\mathrm{VE}=3 \%\end{array}$ & 1.16 to 4.27 \\
\hline Functional constipation & & Nil & & \\
\hline
\end{tabular}

$\overline{\text { Extraintestinal and sex predictors are presented in order of stepwise selection into the model. Each predictor variable was significant }}$ at $\mathrm{p}<0.05$ in the final model.

$\mathrm{VE}$, variance explained was calculated for the model presented; CI, confidence interval.

\section{Extraintestinal symptoms}

No single EIS (or behaviour) was associated directly with the overall severity and extent of functional gut disturbance (the number of coexistent FGID syndromes present). Quantitative effects were found only within the specific associations reported below; thus, extraintestinal symptoms (EIS) were predictive of the combination of FD and IBS in general, and of DL and RL dyspepsia in particular (table 4). Post hoc analysis revealed that fatigue was most likely to be present in patients with both DL dyspepsia and IBS (odds ratio $=4$; $95 \%$ confidence interval $=1.8$ to 9.1 ; $\mathrm{p}=0.0006$ ) while the probability of unpleasant taste was similarly greater in patients with both DL and RL dyspepsia (odds ratio $=5 ; 95 \%$ confidence interval $=2.2$ to $13.5 ; \mathrm{p}=0.0003$ ). In contrast, the relations of binge eating behaviour and of dry skin to RL dyspepsia were robust and highly specific to this syndrome alone. All of the above relations remained significant after controlling for stress (chronic), emotional distress (current), and demographic (age and sex) variables.

\section{EMOTIONAL DISTRESS}

The vast majority of FGID patients (98\%) had been exposed to at least one chronic social stressor, in at least one (of seven) life stress domains (fig 1), for more than a year. Most chronic stressor situations involved role change and/or interaction difficulties; other problems arose in the context of caring for others, or from personal injury, accident, or illness (other than FGID); the remainder involved work, marital, financial, or housing difficulties. On average, patients had been exposed to $2.4(0.6)$ such stressors, for an average of 3.9 (4.3) years; most stressors $(434 / 451,95 \%)$ were current at interview. For $87 \%$ of all patients (FD significantly more than IBS, and IBS significantly more than non-IBS/FD), at least one chronic stressor was objectively rated as severe (highly threatening and/or highly goal frustrating), and was independent of gastrointestinal symptoms. These prevalence rates were uncommonly high - for example, in comparison with our community life stress data, ${ }^{46}$ more FGID patients than healthy individuals were exposed to one or more stressor (98\% versus $36 \%)$; these differences increased as the number of stressors increased (for example, $38 \%$ versus $0 \%$ for three or more stressors), and as their severity increased ( $87 \%$ versus $13 \%$ when at least one stressor was severe). Consistent with the cognitive emotional distress arising from exposure to chronic stressors, state anxiety and/or depression was elevated within the patient sample. For the majority of patients (93\% and $70 \%$ respectively), however, anxiety and depression scores were more indicative of emotional distress than of an emotional disorder of clinical significance.

RELATIONS BETWEEN CHRONIC STRESSORS AND GASTROINTESTINAL, EXTRAINTESTINAL, AND EMOTIONAL SYMPTOMATOLOGIES

Significant linear relations were present between each of three dimensions-number of 


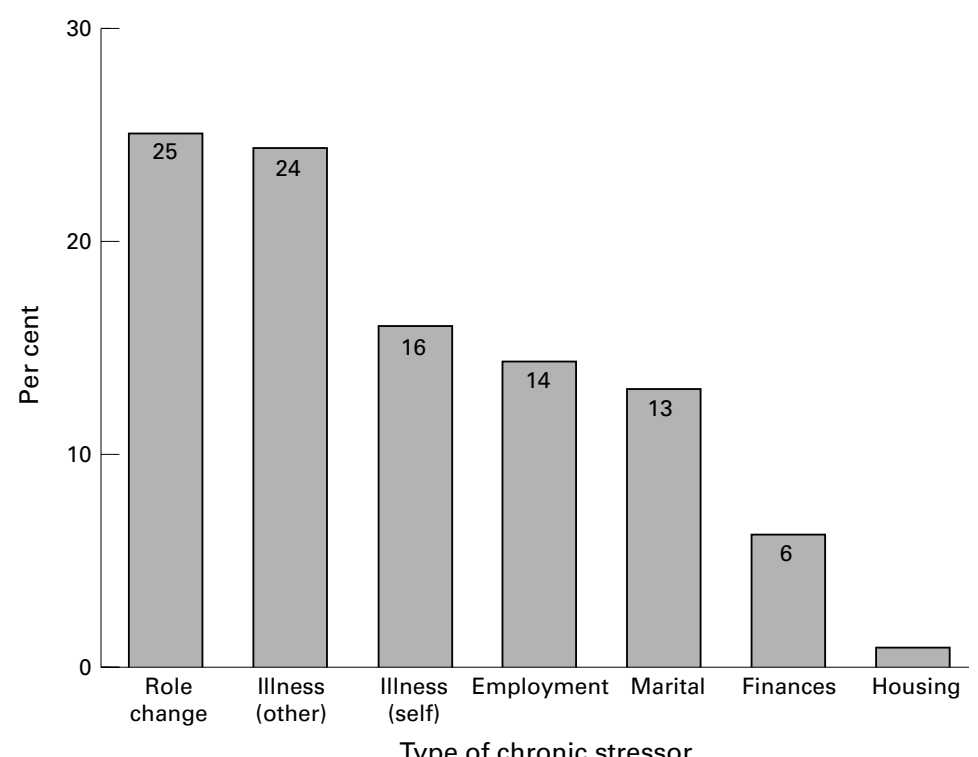

Figure 1 Distribution of chronic stressors $(n=451)$ across seven life stress categories; percentages represent the relative frequency of each category of chronic stressors (as a proportion of all chronic stressors).

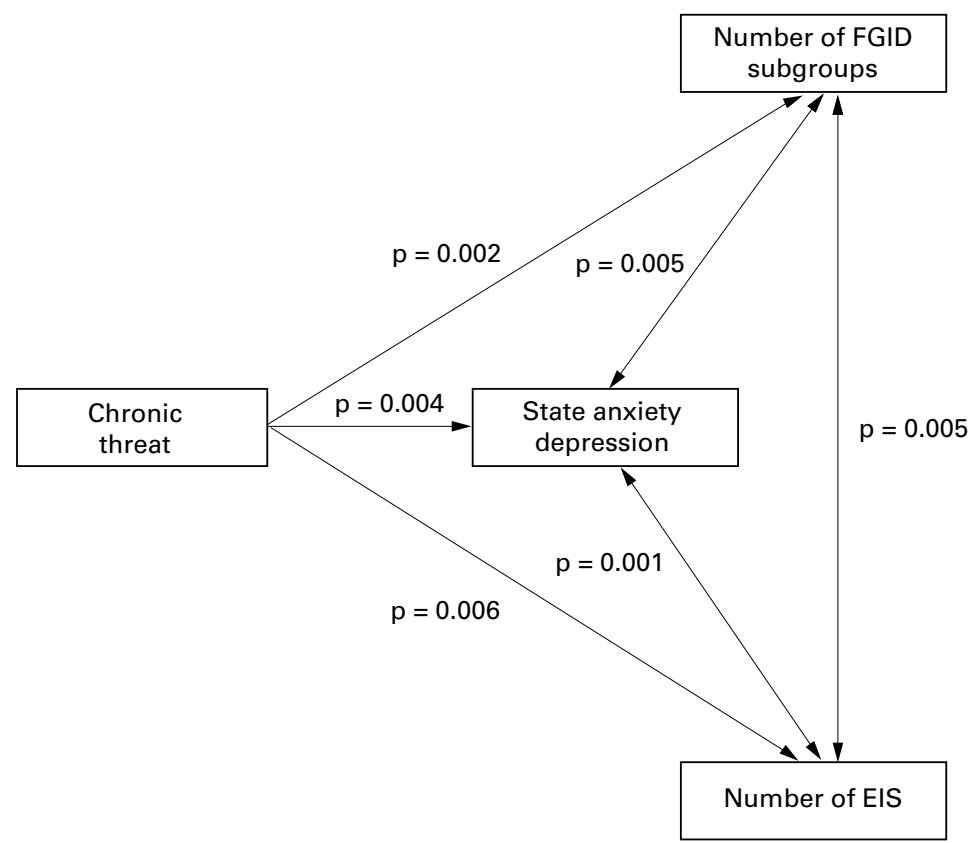

Figure 2 Graphic representation of the three way linear relation between emotional symptoms (anxiety, depression), the number of FGID subgroups present in an individual, and the number of extraintestinal symptoms (EIS); and the effects on each of these dimensions of chronic social stressor threat. Probability values are shown for each linear relation determined from Pearson correlation analysis.

FGID syndromes, number of EIS, and severity of emotional distress (state anxiety, but also depression, anger, and goal frustration). Furthermore, the severity and/or extent of each of these global dimensions varied significantly in accordance with the extent and severity of chronic social stressor threat (fig 2). These global findings were, however, marked by a high degree of specificity - that is, the strength of the linear associations was explained almost entirely by the presence of chronic social stressor threat, anxiety, certain EIS (fatigue, unpleasant taste, binge eating, etc) and certain FGID syndromes (DL and RL dyspepsia and IBS).

\section{Discussion}

This study extends considerably previous research concerning the coexistence of psychological, social, and extraintestinal disturbances in FGID. The methodology which we used (comprehensive and detailed interview based ratings of chronic social stressors ${ }^{14}$ and emotional support, ${ }^{16}$ together with classification of the FGID ${ }^{1}$ ) provided a high degree of objectivity to the study. Novel information included the finding that, although the overall severity and extent of functional gut disturbance increased in parallel with the severity of psychological, social, and extraintestinal disturbance, relations within this general pattern were marked by a high degree of specificity. In particular, high levels of non-gut disturbance (featuring chronic social stressors, together with concurrent extraintestinal and emotional symptomatology) were distinctive of FD and IBS syndromes alone, thus identifying a clinically distinct subgrouping of functional gut disorders characterised by abdominal pain and/or discomfort. Furthermore, in patients with one or more FGID syndromes, chronic social stressor threat, unusual in the community ${ }^{14}$ and yet highly prevalent in patients with FGID, ${ }^{34}$ strongly predicted both the nature and the extent of concurrent multisystem (gastrointestinal, extraintestinal, and emotional) symptomatology. These findings suggest that, in patients with FD and/or IBS, the putative stressor may account, at least in part, for the coexistence of specific functional gut, emotional, extraintestinal, and behavioural disturbances.

The limited representativeness of findings from a single clinical population, in this case from outpatients referred by their primary care physician for endoscopic evaluation, is acknowledged. While findings derived from this population cannot be generalised to either community (non-referred) or hospitalised (more severe) FGID sufferers, an important feature of the present sample is that it provided more than adequate variability within the FGID and psychosocial data to test for within group differences. Further research in a variety of clinical settings is required to determine the general representativeness of these data.

\section{PSYCHOLOGICAL AND SOCIAL DISTURBANCES IN} FGID

The high prevalence of psychosocial disturbance within the FGID patient groupespecially the severity and extent of chronic (social stressor) threat and goal frustration and elevated levels of current anxiety and/or depression-is consistent with previous reports. ${ }^{2-4}$ The highest levels of such psychosocial disturbance, were however, present among patients with the largest number of FGID syndromes. These clusters of syndromes always included at least one FD syndrome (usually DL or RL dyspepsia); IBS was also frequently present. The best combination of dimensions to describe this psychosocial disturbance included: personality (anger reactivity - the tendency to react readily with anger; and neuroticism - a feature predisposing to a more intense and prolonged stress response); chronic 
social stressor threat; increased coping; poor emotional support; and increased age. This profile, which combines psychological, social, and biological elements, is prototypic of the most severe chronic stress scenario. High levels of distress, however, were not distributed evenly across the FGID subgroups-levels of stress (exposure to chronic social stressors) and emotional distress (anxiety and/or depression) were highest in patients with FD syndromes, while distress in the form of hypochondriacal concerns was more prevalent in patients with IBS.

Despite substantial differences in experimental design, the relations found in this study between type of distress and type of FGID support previous associations (for example, depression with DL dyspepsia ${ }^{27}$; hypochondriasis with IBS $^{28-30}$; and emotional distress (anxiety and depression) with heartburn/reflux ${ }^{31}$ ). The present findings, however, shed further light on how personality, chronic social stressors, and distress may differentially influence the development and/or exacerbation of FGID. From our data, it seems reasonable to hypothesise that certain psychophysiological inheritance factors $^{32}$ may predispose to certain types of FGID and/or to more severe and extensive gut symptomatology — in particular, trait anger with FD syndromes (especially UL and RL dyspepsia), and anger reactivity and neuroticism with a larger number of FGIDs. From a biopsychosocial perspective, exposure to chronic and severe stressors may thus determine when FGID is triggered and/or exacerbated, while the angerreactive stress profile suggests that it is the combination of personality and chronic social stress that determines the extent of FGID symptomatology over time. It is of interest that this particular combination of psychosocial factors seems to be also linked to intestinal sensorimotor dysfunction in patients with these syndromes. $^{33}$ It remains to be determined whether chronic overactivity of the sympathetic nervous system ${ }^{34}$ is integral to this process.

EXTRAINTESTINAL DISTURBANCE IN FGID

Similar to psychosocial disturbance, extraintestinal (somatic) symptoms were associated exclusively with the FD-IBS group of syndromes, especially with DL and RL dyspepsia. The prominence of fatigue and unpleasant taste with DL dyspepsia, and with pairs of syndromes that include DL dyspepsia (DL-IBS and DL-RL respectively), is of particular interest. In each case, type of syndrome was specified, and the effects were linear. While both sets of associations are consistent with clinical experience, the nature of the relation between fatigue and dysmotility-like symptomatology remains unclear. Our findings indicate, however, that this relation is independent of chronic social stressors, depression, age, sex, the severity and constancy of pain and/or discomfort, and the number of FGIDs. The relation of binge eating behaviour and dry (eczema-like) skin to a single syndrome, RL dyspepsia, was robust and highly specific. Binge eating behaviour has been associated previously with functional gut symptoms, ${ }^{12}{ }^{35}$ delayed gastric emptying (in patients with eating disorders), ${ }^{36}$ and anxiety/depressive disorders in patients with IBS. ${ }^{35}$ Our findings extend these reports by identifying RL dyspepsia as the most likely of the FGID syndromes assessed in this study to be associated with this behaviour. Furthermore, although binge eating behaviour seems to be provoked by anxiety (and frustration), the effects of binge eating on RL dyspepsia far exceeded the effects of anxiety alone. It seems therefore, that irrespective of the presence of anxiety and even in the absence of self induced vomiting, habitual binge eating behaviour substantially increases the likelihood of RL dyspepsia. The clinical relevance of the relation between dry (eczemalike) skin and RL dyspepsia is not clear.

\section{MULTISYSTEM DISTURBANCE IN FGID}

Multisystem symptomatology is thought to be in part a response to stress that is quantitative and involves physiological changes, elements of somatisation, or a mixture of both. ${ }^{37}$ Furthermore, the disturbance seems to be not simply a characteristic of those who seek treatment, ${ }^{937}$ or a reflection of extreme illness behaviour. ${ }^{7}$ Our findings among patients with FGID are entirely consistent with these empirically based concepts. A new finding, however, was that emotional distress (in particular anxiety) was not associated with a random selection of symptoms; instead there was a high degree of specificity in terms of the particular gastrointestinal syndrome, extraintestinal symptom, or behaviour that was involved. Also, the severity and extent of this psychophysiological disturbance seemed to be determined by the severity and extent of high levels of severe chronic threat in the person's life over at least the previous 12 months, but usually for years.

\section{CONCLUSION}

In conclusion, the present study has shown notable differences between the various FGID subgroups - in particular, chronic stressor provoked emotional and extraintestinal disturbances were most specific for the FD-IBS group of syndromes. While these findings support the symptom based classification of FGIDs, they should now be compared with findings from other clinical (patient and community) groups. The study also suggests that unremitting chronic stress may continue to increase the severity and extent of gastrointestinal, emotional, and extraintestinal symptoms over time. The clinical usefulness of FGID subgrouping will ultimately depend on the extent to which it identifies patients who will respond to specific types of management. Our results suggest that psychological management procedures that target specific aspects of chronic stress and its sequelae may prove most beneficial to FGID patients with multisystem symptomatology; however, early intervention may inhibit the development of such severe and extensive disorders, particularly in patients with FD and/or IBS.

The help and support of members of the Department of Gastroenterology, Royal North Shore Hospital, and that of Dr P Evans, is gratefully acknowledged. 
1 Drossman DA. The functional gastrointestinal disorders. Diagnosis, pathophysiology, and treatment. Boston: Little, Brown \& nosis, pathoph

2 Whitehead WE. Psychosocial aspects of functional gastrointestinal disorders. Gastroenterol Clin North Am 1996;25:2134.

3 Craig TK, Brown GW. Goal frustration and life events in the etiology of painful gastrointestinal disorder. $\mathcal{F}$ Psychosom Res 1984;28:411-21.

4 Bennett EJ, Beaurepaire J, Langeluddecke P, et al. Life stress and non ulcer dyspepsia: a case-control study. F Psychosom Res 1991;35:579-90.

5 Whorwell PJ, McCallum M, Creed F, et al. Non-colonic features of irritable bowel syndrome. Gut 1986;27:37-40.

6 Colgan S, Creed F, Klass H. Symptom complaints, psychiatric disorder and abnormal illness behaviour in patients
with upper abdominal pain. Psychol Med 1988;18:887-92.

7 Talley NJ, Phillips SJ, Bruce B, et al. Multisystem complaints in patients with irritable bowel syndrome and complaints in patients with irritable bowel syndrome and $71-7$.

8 Haug TT, Svebak S, Wilhelmsen I, et al. Psychological factors and somatic symptoms in functional dyspepsia. A comparison with duodenal ulcer and healthy controls. $\mathcal{F}$ Psychosom Res 1994;38:281-91.

9 Gomborone JE, Mulcahy H, Dewsnap P, et al. Non-colonic symptoms and consultation status in irritable bowel syndrome and functional bowel disorder [abstract]. Gastroenterology 1995;108:A606.

10 Talley NJ, Phillips SF, Melton LJ, et al. A patient questionnaire to identify bowel disease. Ann Intern Med 1989;111: 671-4.

11 Talley NJ, Boyce PM, Owen BK, et al. Initial validation of a bowel symptom questionnaire and measurement of chronic gowe symptin questionnaire and measurement of chronic 1995;25:302-8.

12 Drossman DA, Thompson WG, Talley NJ, et al. Identification of sub-groups of functional gastrointestinal disorders. tion of sub-groups of functional gastrointestinal

13 Crowell MD, Cheskin LJ, Musial F. Prevalence of gastrointestinal symptoms in obese and normal weight binge eaters. testinal symptoms in obese and norm

14 Brown GW, Harris TO. Social origins of depression: a study of psychiatric disorder in women. London: Tavistock, 1978.

15 Tennant C, Smith A, Bebbington P, et al. The contextua threat of life events: the concept and its reliability. Psychol Med 1979;9:525-8

16 Henderson S. A development in social psychiatry: the systematic study of social bonds. 7 Nerv Ment Dis 1980;168:63-9.

17 Radloff LS. The CES-D scale: a self-report depression scale for research in the general population. Applied Psychological Measurement $1977 ; 1: 385-401$.

18 Spielberger CD, Gorsuch RL, Lushene R, et al. Manual for the state-trait anxiety inventory STAI (Form Y). Palo Alto, CA: Consulting Psych Press Inc., 1983.

19 Grayson D. A latent trait analysis of Eysenck Personality Questionnaire. F Psychosom Res 1986;20:217-35.
20 Spielberger CD, Jacobs G, Russell S, et al. Assessment of anger: the State-Trait Anger Scale. In: Butcher JN, Spielberger CP, eds. Advances
2. Hillsdale, NY: LEA, 1983.

21 Pilowsky I, Spence ND. Manual for the illness behaviour questionnaire $(I B Q)$. 2nd edn. Adelaide, Australia: University of Adelaide, 1983.

22 Andrews G, Singh M, Bond $M$. The Defense Style Questionnaire. F Nerv Ment Dis 1993;181:246-56.

23 Watson M, Greer S. Development of a questionnaire measure of emotional control. F Psychosom Res 1983;27:299305.

24 Spielberger CD, Johnson EH, Jacobs GA, et al. The Anger Expression (AX) Scale. Unpublished manuscript. Centre for Behavioral Medicine and Community Psychology, Human Resources Institute, University of South Florida, Tampa, Florida, USA, 1987.

25 Bebbington P, Hurry J, Tennant C, et al. Epidemiology of mental disorders in Camberwell. Psychol Med 1981;11: 561-79.

26 Gilligan I, Fung L, Piper GW, et al. Life events and chronic difficulties in duodenal ulcer: a case control study. $\mathcal{F}$ Psychosom Res 1987;31:117-23.

27 Kaneko H, Mitsuma T, Fujii S, et al. Immunoreactivesomatostatin concentrations of the human stomach and mood state in patients with functional dyspepsia: a preliminary case-control study. F Gastroenterol Hepatol 1993;8: $322-7$.

28 Ford MJ. The irritable bowel syndrome. 7 Psychosom Res 1986;30:399-410.

29 Drossman DA, McKee DC, Sandler R, et al. Psychosocial factors in the irritable bowel syndrome: a multivariate study of patients and nonpatients with irritable bowel syndrome. Gastroenterology 1988;95:701-8.

30 Gomborone J, Dewsnap P, Libby G, et al. Abnormal illness attitudes in patients with irritable bowel syndrome. $\mathcal{F}$ Psychosom Res 1995;39:227-30.

31 Johnston BT, Lewis SA, Love AH. Stress, personality and social support in gastro-oesophageal reflux disease. $\mathcal{f}$ Psychosom Res 1995;39:221-6.

32 Eysenck HJ, Eysenck MW. Personality and individual differences. London: Plenum Press, 1985.

33 Evans PR, Bennett EJ, Bak, Y-K, et al. Jejunal sensorimotor dysfunction in irritable bowel syndrome: clinical and dysfunction in irritable bowel syndrome: clinical and
psychosocial features. Gastroenterology 1996;110:393-404.

psychosocial features. Gastroenterology 1996;110:393-404.
34 Heitkemper M, Jarrett M, Cain K, et al. Increased urine catecholamines and cortisol in women with irritable bowel echolamines and cortisol in women with irrit
syndrome. Am $\mathcal{f}$ Gastroenterol 1996;91:906-13.

35 Guthrie EA, Creed FH, Whorwell PJ. Eating disorders in patients with the irritable syndrome: a comparison with inflammatory bowel disease and peptic ulceration. Eur $\mathcal{f}$ Gastroenterol Hepatol 1990;2:471-3.

36 Inui A, Okano $\mathrm{H}$, Miyamoto $\mathrm{M}$, et al. Delayed gastric emptying in bulimic patients [letter]. Lancet 1995;346:1240.

37 Kellner R. Psychosomatic syndromes and somatic symptoms. Washington, DC: American Psychiatric Press, Inc., 1991. 